\title{
Solving delay differential equations by successive interpolations
}

\section{AleXANDRU MiHai BiCA}

\section{ABSTRACT.}

In this paper we construct the new method of successive interpolations for functional differential equations using the interpolation procedure of cubic splines generated by initial conditions. The convergence and the numerical stability of the method are proved and tested on some numerical examples.

\section{REFERENCES}

[1] Ahlberg, J. H., Nilson, E. N. and Walsh, J. L., The theory of splines and their applications, Academic Press, New York, London, 1967

[2] Bellen, A. and Zennaro, M., Numerical methods for delay differential equations, Oxford University Press, Oxford, 2003

[3] Brunner, H., Collocation methods for Volterra integral and related functional differential equations, Cambridge University Press, Cambridge, 2005

[4] Cerone, P. and Dragomir, S. S., Trapezoidal-type rules from an inequalities point of view, in Handbook of analytic-computational methods in applied mathematics (G. A. Anastassiou, Ed.), Chapman \& Hall/ CRC Press Boca Raton, London, New York Washington DC, 2000, 65-134

[5] Chen, X. and Wang, L., The variational iteration method for solving a neutral functional-differential equation with proportional delays, Comput. Math. Appl., 59 (2010), 2696-2702

[6] El-Hawary, H. M. and Mahmoud, S. M., Spline collocation methods for solving delay-differential equations, Appl. Math. Comput., 146 (2003), 359-372

[7] Enright, W. H. and Hayashi, H., A delay differential equation solver based on a continuous Runge-Kutta method with defect control, Numer. Algor., 16 (1997), 349-364

[8] Evans, D. J. and Raslan, K. R., The Adomian Decomposition Method for solving delay differential equation, Int. J. Comput. Math., 82 (2005), 49-54

[9] Feldstein, A., Convergence and asymptotic error expansion for Euler's method for variable delay differential equations, Appl. Num. Math., 56 (2006), 271-283

[10] Guglielmi, N. and Zennaro, M., Stability of the one-leg $\theta$-methods for the variable coefficient pantograph equation on the quasi-geometric mesh, IMA J. Numer. Anal., 23 (2003), 421-43

[11] Iancu, C., On the cubic spline of interpolation, Sem. Funct. Anal. Num. Meth. Cluj-Napoca, 4 (1981), 52-71

[12] Ishiwata, E. and Muroya, Y., Rational approximation method for delay differential equations with proportional delay, Appl. Math. Comput., 197 (2007), 741-747

[13] Micula, G. and Micula, S., Handbook of splines, Mathematics and its Applications 462, Kluwer Acad. Publ., Dordrecht, 1999

[14] Muresan, A. S., Step method for a functional-differential equation from mathematical economics, Carpathian J. Math., 24 (2008), 356-362

[15] Ockendon, J. R. and Taylor, A. B., The dynamics of a current collection system for an electric locomotive, Proc. Roy. Soc. London Ser. A, 322 (1971), 447-468

[16] Ramadan, M. A., Spline solutions of first delay differential equations, J. Egypt. Math. Soc., 13 (2005), 7-18

[17] Shampine, L. F., Solving ODE's and DDE's with residual control, Appl. Numer. Math., 52 (2005), 113-127

Received: 20.12.2011; In revised form: 03.11.2012; Accepted: 12.12.2012

2010 Mathematics Subject Classification. 34K28.

Key words and phrases. Functional differential equations, successive interpolations, numerical method, cubic splines generated by initial conditions. 
DEPARTMENT OF MATHEMATICS AND INFORMATICS

UNIVERSITY OF ORADEA

UNIVERSITAŢII 1, 410087 ORADEA, ROMANIA

E-mail address: abica@uoradea.ro 